\title{
Behavioral variant of frontotemporal dementia
}

INSERM

\section{Source}

INSERM. (1999). Orphanet: an online rare disease and orphan drug data base. Behavioral variant of frontotemporal dementia. ORPHA:275864

Behavioral variant of frontotemporal dementia (bv-FTD) is a form of frontotemporal dementia (FT D; see this term), characterized by progressive behavioral impairment and a decline in executive function with frontal lobe-predominant atrophy. 